\title{
Perbandingan Waktu Pengukuran Pipet Ukur Glasfirn Pi Pump dan Micropipet Socorex pada Uji TPCAcetobacter xylinum
}

\author{
Rini Nuraini Rohmatningsih ${ }^{1}$ \\ 1Departemen Teknologi Industri Pertanian, Fakultas Teknologi Pertanian, Universitas \\ Gadjah Mada, JI. Flora No.1 bulaksumur, Depok Sleman Yogyakarta, \\ Email: nutrien@ugm.ac.id
}

Submisi: 12 Agustus 2020; Penerimaan: 15 Desember 2020

\begin{abstract}
ABSTRAK
Salah satu kegiatan yang dilaksanakan di laboratorium Bioindustri saat ini adalah pengukuran karakteristik pertumbuhan Acetobacter xylinum. Karakteristik pertumbuhannya diukur pada rentang waktu hari ke-1 sampai ke-8 dengan inkubasi pada suhu $30^{\circ} \mathrm{C}$. Untuk pemeriksaan beberapa sampel dengan pengulangan tiga kali membutuhkan waktu lama. Penelitian ini bertujuan untuk membandingkan efektifitas penggunaan Glasfirn Pi Pump dan Micropipet Socorex sebagai alat bantu memindahkan cairan dari satu tempat ke tempat yang laindalam penanaman bakteri Acetobacter xylinum. Waktu pengukuran volume $0,1 \mathrm{ml}$ dan 1,0 ml menggunakan Glasfirn Pi Pump dan Micropipet Socorex dihitung menggunakan Stopwatch dengan pengulangansebanyak 30 kali untuk masing-masing pipet. Data yang diperoleh di uji beda menggunakan software SPSS. Berdasarkan penelitian yang telah dilakukan diperoleh hasil, bahwa waktu tercepat pemipetan $0,1 \mathrm{ml}$ dan $1,0 \mathrm{ml}$ menggunakan Glasfirn Pi Pump adalah 37,52 detik dan 37,36 detik dan waktu tercepat pemipetan $0,1 \mathrm{ml}$ dan 1,0 ml menggunakan Micropipet Socorex adalah 26,37 detik dan 21,28 detik. Hasil statistic ujibeda menunjukkan bahwa sebaran data berbeda nyata pada pemipetan 0,1 $\mathrm{ml}$ dan 1,0 ml, sehingga dapat disimpulkan bahwa Micropipet Socorex dapat memindahkan cairan lebih cepat.
\end{abstract}

Kata kunci : Glasfirn pi pump; micropipet socorex; uji TPC; Acetobacter Xylium.

\section{PENDAHULUAN}

Saat ini penelitian tentang bakteri Acetobacter xylinum sedang dilaksanakan di laboratorium Bioindustri. Produk ini berasal dari aktivitas kumpulan sel bakteri pembentuk kapsul seperti Acetobacter xylinum yang berupa lapisan polisakarida ekstraseluler (selulosa). Lapisan tersebut memiliki tekstur yang kenyal, berwarna putih,menyerupai gel, dan berada pada bagian permukaan cairan substrat (Rizal dkk., 2013). Bakteri Acetobacter xylinum adalah bakteri Gram negatif, berbentuk batang, mikroaerofilik, bersifat katalase positif, dan termasuk ke dalam kelompok bakteri asam asetat (Budiarti, 2008). Bakteri tersebut dapat tumbuh dan berkembang membentuk nata karena adanya kecukupan kandungan air, protein, lemak, dan karbohidrat di dalam substrat. Selain itu, pertumbuhan bakteri Acetobacter xylinum juga dipengaruhi oleh berbagai faktor lainnya seperti $\mathrm{pH}$ dan suhu (Rizal dkk., 2013). Faktorfaktor yang dapat mempengaruhi hasil fermentasi tersebut adalah suhu inkubasi, komposisi substrat, $\mathrm{pH}$ atau derajat keasaman media, serta kuantitas dan kualitas starter (inokulum) yang digunakan (Rizal dkk.,2013).

Untuk mengetahui jumlah bakteri yang hidup maka diperlukan metodeTPC (Total Plate Count). Pada tahap ini dilakukan pemipetan untuk pengambilan 
bakteri Acetobacter xylinum dari larutan pengencer kemudian ditanam pada media nutrien agar. Untuk menghindari kontaminasi diperlukan pemilihan jenis pipet yang tepat. Dalam penelitian ini dipilih Glassfirn pipet dan Mikropipet Socorex untuk mengetahui waktu tercepat dalam tahapan pemipetan. Penelitian ini bertujuan membandingkan efektifitas penggunaan Glasfirn Pi Pump dan Mikropipet Socorex sebagai alat bantu memindahkan cairan dalam penanaman bakteri. Acetobacter xylinum. Salah satu alat laboratorium yang digunakan untuk memindahkan cairan adalah pipet ukur.

Untuk memindahkan cairan dalam volume kecil (hingga ukuran mikro liter) dapat digunakan mikropipet. (Anonim²,2004) Sama seperti dengan fungsi pipet ukur atau pipet volume, fungsi mikropipet ini adalah untuk memindahkan larutan atau cairan dari satu tempat ke tempat yang lainnya, tetapi untuk volume yang sangat kecil (dibawah $1,0 \mathrm{ml}$ ). Penggunaan pipet ukur dibawah $1,0 \mathrm{ml}$ tidak memiliki akurasi yang tinggi sehingga mikropipet dipilih karena mempunyai akurasi dan presisi yang lebih baik dari pipet ukur. Mikropipet dapat diatur volumenya sesuai dengan keinginan sampai batas skala volume pipet tersebut.

\section{METODE PENELITIAN}

\section{Bahan-bahan}

Air, Etanol 99\%, Spritus, Agar teknis, $\mathrm{CaCO}_{3}$, Yeast ekstrak, Glukosa.

\section{Peralatan}

Glasfirn Pi Pump, Mikropipet Socorex, Stopwatch, Pipet Ukur 0,1 ml \& $1,0 \mathrm{ml}$, Tip Blue dan yellow, tabung reaksi, cawan petri, vortex, Autoclave, Inkubator. Gambar Micropipet dapat dilihat pada Gambar 1, sedangkan gambar glasfirn pi pump dapat dilihat pada Gambar 2. Fungsi bagian-bagain Micropipet andalah sebagai berikut :

1. Plunger button/ tombol penekan, yang berfungsi untuk memompa larutan atau cairan dengan cara menekan tombol tersebut.

2. Tips ejector button, yang berfungsi untuk melepaskan tips setelah selesai digunakan dengan cara menekan tombol tersebut.

3. scale volume/skala volume, bagian yang menunjukkan angka/ volume pengambilan cairan sesuai yang diinginkan. untuk mengatur volume putar-putar bagian bawah plunger button ( pada gambar kiri )

4. Shaft/ batang ujung mikropipet, yang berfungsi untuk menghubungkan mikropipet dengan tips.

5. Pipette tips, yang berfungsi untuk menampung larutan atau cairan yang dipipet. Pemilihan tip sangat penting untuk menentukan keakuratan dalam pemipetan. Penggunaan tip sebaiknya disesuaikan dengan merek yang sama dengan pipetnya karena tidak semua pipet cocok dengan semua tip yang tersedia.(Anonim²,2004)

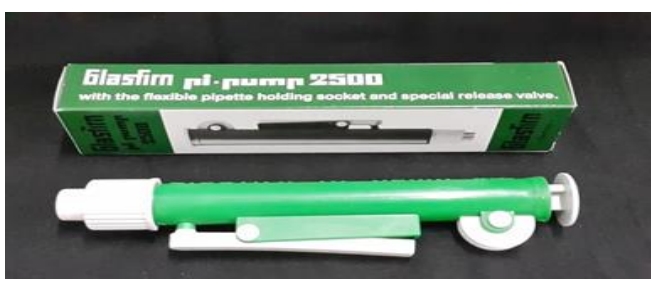

Gambar 2. Glasfirn Pi Pump (Sumber: Anonim ${ }^{1}$.1997) 

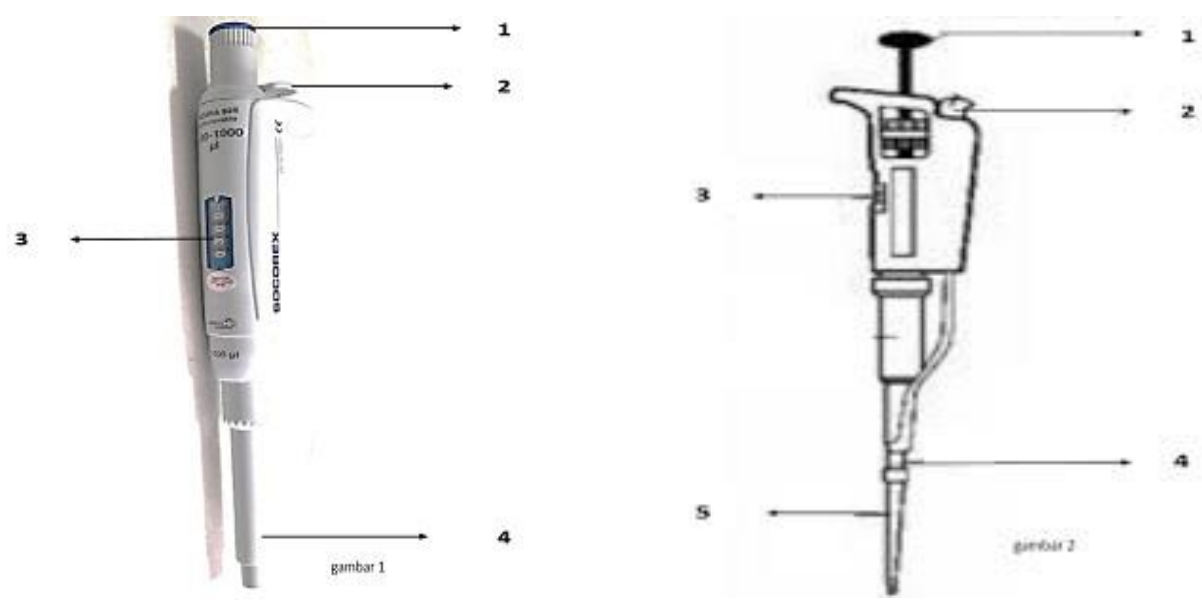

Gambar 1. Bagian-bagian Micropipet Socorex: 1. Plunger button/ tombol penekan, 2. Tip's ejector button, 3. scale volume/skala volume, 4. Shaft/ batang ujung mikropipet, 5. Pipette tips (Sumber: Anonim².2004)

Adapun cara penggunaan Glasfirn pi-pump adalah dengan memasukkan pipet ukur $1 \mathrm{ml}$ dan $0,1 \mathrm{ml}$ pada lubang, kemudian putar-putar piston untuk menarik cairan (Anonim ${ }^{1}$,1997). Cara Kerja Glasfirn Pi Pump adalah sebagai berikut :

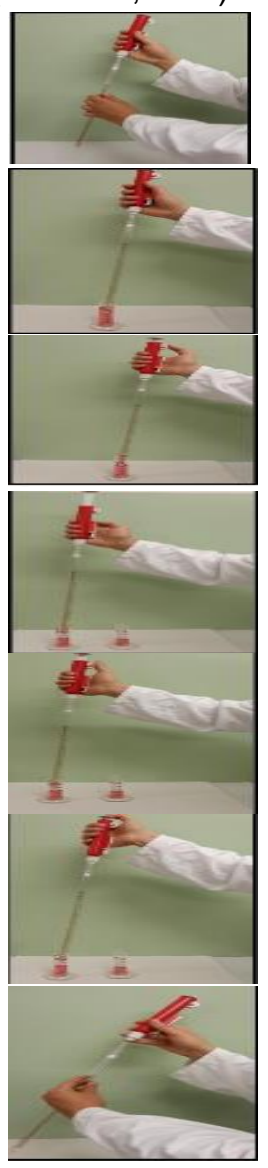

Masukkan pipet dengan hati - hati ke dalam kerucut sambil dilakukan tekanan ringan.

Masukkan bagian atas pipet ke dalam cairan

Turunkan roda knurled ke bawah untuk mengisap naik cairan.

Lepaskan tuas untuk melepas semua cairan

Untuk melepaskan cairan secara tepat sesuai ukuran yang dikehendaki, ikuti baris demi baris skala ukur, dan putar kembali roda.

Menurunkan piston bisa melepaskan cairan lebih cepat.

Setelah selesai bekerja, tarik pipet dengan lembut untuk melepasnya dari kerucut. 


\section{Waktu dan tempat}

Penelitian dilaksanakan pada tanggal 30 Januari 2019 sampai dengan tanggal 10 Maret 2019 di Laboratorium Bioindustri Departemen Teknologi Industri pertanian FTP UGM.

\section{Prosedur penelitian}

Menumbuhkan

Acetobacter

xilinum secara enumerasi dengan memindahkan $0,1 \mathrm{ml}$ dan $1,0 \mathrm{ml}$ cairan ke dalam cawan petri yang berbeda menggunakan Glasfirn Pi Pump dan Micropipet Socorex, waktu yang diperlukan diukur menggunakan stopwatch.

1. Pembuatan Media agar asam asetat

Larutkan $20 \mathrm{~g}$ Glukosa, $5 \mathrm{~g}$ Yeast Extract, $10 \mathrm{~g}$ Agar teknis, $20 \mathrm{~g} \mathrm{CaCO}_{3}, 50$ $\mathrm{ml}$ Etanol $99 \%$ ke dalam 1 liter aquadest, kemudian dipanaskan sampai agar larut. Media siap disterilisasi(Nurika dan Hidayat,2001).

2. Pembuatan larutan pengencer Aquadest $9 \mathrm{ml}$ dimasukkan dalam tabung reaksi, ditutup dengan sumbat dan siap disterlisasi. (Nurika dan Hidayat,2001)

3. Plating

Kultur Acetobacter xylinum 1,0 ml dipipet dimasukkan cawan petri secara aseptis kemudian dituangi media agar asam asetat( metode pour plate). Media agar asam asetat dituang ke cawan petri steril setelah memadat dituang kultur Acetobacter xylinum $0,1 \mathrm{ml}$ secara aseptis (metode spread plate). Seri pengenceran yang dilakukan sampai 10

6 Kultur bakteriAcetobacter xilinum. Biakan cawan petri disimpan dalam inkubator pada suhu $30^{\circ} \mathrm{C}$ selama 5 hari. Koloni yang tumbuh dihitung dan disajikan pada Gambar 3. $\left(\right.$ Anonim $\left.{ }^{3}, 2018\right)$

\section{Teknis analisis data}

Uji beda merupakan bagian dari pengujian statistik. Uji beda terdiri dari uji beda sampel berpasangan dan sampel tidak berpasangan. Sebelum dilakukan uji beda, terlebih dahulu dilakukan uji normalitas untuk mengetahui distribusi data yang ada. Apabila data berdistribusi normal maka uji yang dilakukan adalah uji parametrik independent sample $T$ Test, sedangkan jika data tidak berdistribusi normal maka uji yang dilakukan adalah uji non parametrik Mean-Whitney Test. Tingkat signifikansi yang digunakan pada penelitian ini adalah 0,05 karena tingkat signifikansi ini merupakan salah satu yang umum digunakan (Sudjana, 2005).

\section{HASIL DAN PEMBAHASAN}

Berdasarkan hasil penelitian didapatkan hasil pengukuran pipet $0,1 \mathrm{ml}$ dan $1 \mathrm{ml}$ dengan pengulangan 15 kali, Tabel 1. Waktu tercepat pemipetan 0,1 $\mathrm{ml}$ dan $1,0 \mathrm{ml}$ menggunakan Glasfirn $\mathrm{Pi}$ Pump adalah 37,52 detik dan 37,36 detik. Adapun waktu tercepat pemipetan $0,1 \mathrm{ml}$ dan $1,0 \mathrm{ml}$ menggunakan Micropipet Socorex adalah 26,37 detik dan 21,28 detik. Data tersebut kemudian dianalisis menggunakan SPSS untuk mengetahui perbedaan nyata antara waktu pengukuran larutan volume $0,1 \mathrm{ml}$ dan 1,0 ml menggunakan Glasfirn pi pump dan micropipet socorex. Beberapa tahapan dalam analisis data menggunakan SPSS.

\section{Volume $0,1 \mathrm{ml}$}

Tahap pertama analisis data adalah Uji Normalitas. Pengujian normalitas dilakukan untuk menentukan metode analisis statistik yang cocok untuk mengolah data. Hasil pengujian normalitas data dapat dilihat pada Tabel 2. Hasil analisis data statistik nonparametrik untuk pipet volume $0,1 \mathrm{ml}$ dapat dilihat pada Tabel 3. 
Tabel 1. Data pengukuran waktu dalam detik

\begin{tabular}{ccccc}
\hline & \multicolumn{2}{c}{$\begin{array}{c}\text { Volume Pemipetan } \\
\text { Ulangan }\end{array}$} & \multicolumn{2}{c}{$\begin{array}{c}\text { Volume Pemipetan } \\
\text { pump }\end{array}$} \\
& $0,1 \mathrm{ml}$ & $1,0 \mathrm{ml}$ & $0,1 \mathrm{ml}$ & $1,0 \mathrm{ml}$ \\
\hline 1 & 44,59 & 37,36 & 32,48 & 24,82 \\
2 & 37,89 & 38,48 & 31,34 & 21,28 \\
3 & 38,22 & $38,60^{\prime}$ & 26,37 & $24,50^{\prime}$ \\
3 & 38,59 & 39,04 & 31,12 & 29,55 \\
4 & 39,03 & 39,75 & 33,03 & 30,32 \\
5 & 38,43 & 41,23 & 32,29 & 30,57 \\
6 & 37,52 & 40,44 & 31,86 & 32,42 \\
7 & 41,95 & 39,35 & 32,48 & 31,65 \\
8 & 40,48 & 40,21 & 33,18 & 29,85 \\
9 & 38,62 & 41,32 & 27,25 & 31,15 \\
10 & 39,21 & 40,52 & 27,83 & 30,56 \\
11 & 38,41 & 39,82 & 26,63 & 32,41 \\
12 & 41,89 & 37,54 & 29 & 29,63 \\
13 & 40,52 & 38,24 & 30,04 & 30,72 \\
14 & 39,38 & 39,30 & 31,00 & 28,84 \\
15 & & & &
\end{tabular}

Tabel 2. Uji Normalitas Volume $0,1 \mathrm{ml}$

\begin{tabular}{|c|c|c|c|c|c|c|}
\hline \multirow{2}{*}{$\begin{array}{l}\text { Jenis } \\
\text { Pipet }\end{array}$} & \multicolumn{3}{|c|}{$\begin{array}{l}\text { Kolmogorov- } \\
\text { Smirnova }\end{array}$} & \multicolumn{3}{|c|}{ Shapiro-Wilk } \\
\hline & Statistic & df & Sig. & Statistic & $d f$ & Sig. \\
\hline \multirow{2}{*}{$\begin{array}{l}\text { Pipet } \\
\text { Ukur } \\
\text { tip }\end{array}$} & 0.222 & 15 & 0.045 & 0.860 & 15 & 0.024 \\
\hline & 0.200 & 15 & 0.108 & 0.888 & 15 & 0.063 \\
\hline
\end{tabular}

Berdasarkan hasil normalitas data, data dikatakan normal apabila memenuhi syarat nilai Sig $>0,05$. Nilai sig yang digunakan pada kasus ini adalah nilai sig dari Shapiro-Wilk karena data berjumlah kurang dari 50. Apabila dilihat, nilai sig dari pipet tip lebih dari 0,05 sedangkan nilai sig dari pipet ukur kurang dari 0,05. Data pipet tip bersifat normal, sedangkan data pipet ukur tidak normal. Oleh karena itu metode analisis data statistik yang dipilih adalah statistik non parametrik.
Metode ini dipilih apabila terdapat data yang tidak normal dari keseluruhan data yang diuji normalitasnya.

Berdasarkan hasil analisis data menggunakan metode nonparametrik, didapatkan hasil nilai Asymp.Sig (2tailed) sebesar 0.000 yang dapat diartikan bahwa waktu pengukuran antara pipet ukur dan tip pada volume 0.1 $\mathrm{ml}$ menunjukkan hasil yang berbeda nyata karena hasil nilai Asymp $<0.05$. 
Tabel 3. Uji statistic Volume $0,1 \mathrm{ml}$

\begin{tabular}{ll}
\hline & Waktu \\
\hline Mann-Whitney U & 0.000 \\
Wilcoxon W & 120.000 \\
Z & -4.667 \\
Asymp. Sig. (2-tailed) & 0.000 \\
Exact Sig. [2*(1-tailed Sig.)] & $0.000^{\mathrm{b}}$ \\
\hline a. Grouping Variable: JenisPipet \\
b. Not corrected for ties.
\end{tabular}

Volume $1 \mathrm{ml}$

Pada pembahasan waktu pengukuran larutan volume $1,0 \mathrm{ml}$ menggunakan Glasfirn pi pump dan Micropipet Socorex ini, tahap dan metode yang digunakan untuk analisis data sama dengan pembahasan sebelumnya, hanya saja volume yang digunakan acuan untuk membandingkan kinerja kedua pipet berbeda.

Pada pembahasan kali ini, volume yang digunakan untuk membandingkan kinerja kedua pipet adalah $1,0 \mathrm{ml}$. Langkah awal yang ditempuh untuk melakukan analisis data adalah uji normalitas. Pengujian normalitas dilakukan untuk menentukan metode analisis statistik yang cocok untuk mengolah data. Hasil pengujian normalitas data dapat dilihat pada Tabel 4.

Tabel 4. Uji Normalitas Volume $1 \mathrm{ml}$

\begin{tabular}{ccccccc}
\hline Jenis & \multicolumn{3}{c}{ Kolmogorov-Smirnova } & \multicolumn{3}{c}{ Shapiro-Wilk } \\
Pipet & Statistic & df & Sig. & Statistic & df & Sig. \\
\hline $\begin{array}{c}\text { Pipet } \\
\text { Ukur }\end{array}$ & 0.325 & 15 & 0.000 & 0.581 & 15 & 0.000 \\
Tip & 0.275 & 15 & 0.003 & 0.812 & 15 & 0.005 \\
\hline \multicolumn{4}{c}{ a. } & Lilliefors Significance Correction
\end{tabular}

Berdasarkan hasil normalitas data, data dikatakan normal apabila memenuhi syarat nilai Sig $>0,05$. Nilai sig yang digunakan pada kasus ini adalah nilai sig dari Shapiro-Wilk karena data berjumlah kurang dari 50. Apabila dilihat, nilai sig dari kedua pipet tip kurangdari 0,05. Sehingga data kedua nya tidak normal. Oleh karena itu metode analisis data statistik yang dipilih adalah statistik non parametrik. Hasil analisis data statistik non parametrik untuk pipet volume $1,0 \mathrm{ml}$ dapat dilihat pada Tabel 5.

Berdasarkan hasil analisis data menggunakan metode non parametrik, didapatkan hasil nilai Asymp.Sig (2tailed) sebesar 0.000 yang dapat diartikan bahwa waktu pengukuran antara pipetukur dan tip pada volume 1,0 $\mathrm{ml}$ menunjukkan hasil yang berbeda nyata karena hasil nilai Asymp $<0.05$. Dari Gambar 3 dapat diketahui, pertumbuhan jumlah sel Acetobacter xilinum mulai mengalami peningkatan pada hari ke-4 dimana pada fase ini terjadi pembentukan serat selulosa sebagai hasil metabolit sekundernya.

Tabel 5. Uji statistik Volume $1 \mathrm{ml}$

\begin{tabular}{cc}
\hline & Waktu \\
\hline Mann-Whitney U & 12.500 \\
Wilcoxon W & 132.500 \\
Z & -4.148 \\
Asymp. Sig. (2-tailed) & .000 \\
Exact Sig. [2*(1-tailed Sig.)] & $.000^{\mathrm{b}}$ \\
\hline
\end{tabular}

a. Grouping Variable: JenisPipet

b. Not corrected for ties. 


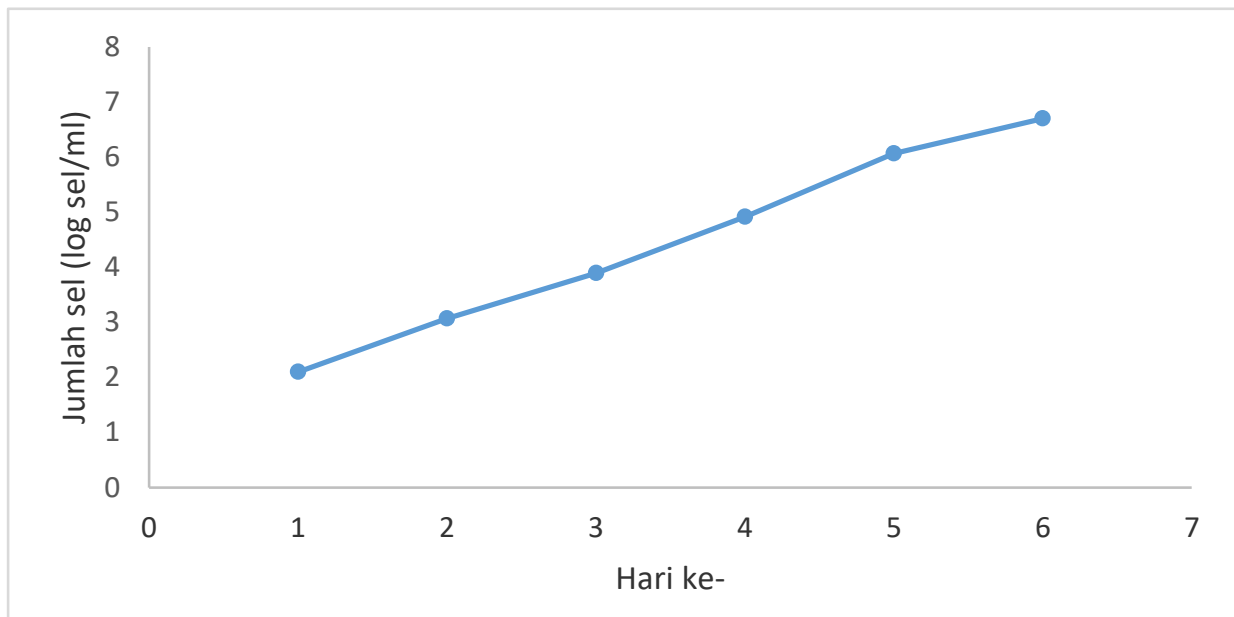

Gambar 3. Uji TPC Acetobacter Xilinum pada hari ke-1 sampai ke-6

\section{KESIMPULAN}

Mikropipet Socorex merupakan piranti yang lebih cepat untuk memindahkan cairan dengan volume 0,1 $\mathrm{ml}$ dan $1,0 \mathrm{ml}$. Waktu pengukuran antara pipet ukur Glasfirn Pi Pump dan tip Micropipet Socorex pada volume $0.1 \mathrm{ml}$ menunjukkan hasil yang berbeda nyata/berbeda secara signifikan karena pada pengujian statistik nilai sigma kurang dari 0,05. Demikian juga antara pipet ukur dan tip pada volume $1,0 \mathrm{ml}$ menunjukkan hasil yang berbeda nyata/berbeda secara signifikan karena pada pengujian statistik nilai sigma kurang dari 0,05.

\section{UCAPAN TERIMAKASIH}

Penulis menghaturkan banyak terimakasih kepada Kepala laboratorium Bioindustri bapak Dr. Jumeri, M.Si yang telah memfasilitasi penelitian ini dan bapak Darmawan Ari STP, MP karena dengan membantu penelitian beliau dapat terwujud ide penelitian ini.

\section{DAFTAR PUSTAKA}

Anonim1.1997. DHT.Glasfirn pi pump Glasfirn Giessen Manual Operating Instruction. Diakses dari www.glasfirn.de tanggal 18 Maret 2019.

Anonim².2004.Digital Reading Micro Pipettes Manual Operating Instruction. Socorex.Switzerland

Anonim³.2018. Modul Mikrobiologi Dasar Tahun ajaran 2018/2019. Yogyakarta:Departem en Teknologi Industri Pertanian UGM.

Budiarti Retni S.2008.Pengaruh Konsentrasi Starter Acetobacter xylinum Terhadap Ketebalan \& Rendemen Selulosa Nata de Soya.Jurnal Universitas Jambi Program Studi P.Biologi, Jurusan P MIPA,FKIP.Vol.1.No.1 Februari 2008, hlm.19-24.

Kurniawan, A. 2010. Belajar mudah SPSS untuk pemula. Yogyakarta: Media Kom

Nurika, Irnia dan Nur Hidayat.2001.Pembuatan Asam Asetat dari Air kelapa Secara Kontinyu Menggunakan Kolom Biooksidasi.Jurnal Teknologi Pertanian, Vol 2, No.1, April 2001: 51-57

Rizal HM, Pandiangan DM, Saleh A. 2013. Pengaruh penambahan gula, asam asetat, dan waktu fermentasi terhadap kualitas nata de corn. J Tek Kim.19(1):34-39.

Sudjana. 2005. Metoda Statistika Edisi 6.Bandung:Tarsito. 